\title{
Adsorption performance of coated bentonite via graphene oxide
}

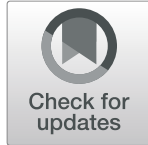

\author{
H H Shaarawy, H S Hussein", E Abdel Kader, Nabila H Hussien and SI Hawash
}

\begin{abstract}
Background: The nano-adsorbents present considerable decontamination potential due to their unique characteristics. This study aimed to investigate the adsorption efficiency and capacity of synthesized nano graphene oxide coated layer over Egyptian clays (bentonite, kaolinite and feldspar) as substrate. The experimental work involves nano graphene oxide coating using acid dehydration via sulfuric acid in presence of different percentage of sugar (fine powder from 1 to 7\%), followed by thermal activation to improve the adsorption capacity of natural clay that is locally available in Egypt. Several operating parameters were studied to prepare the superior adsorbent (type of substrate, sulfuric acid concentration, sugar concentration and contact time).

Results: The optimum preparation conditions of nano graphene oxide coated bentonite (NGOCB) adsorbent were bentonite substrate $1 \mathrm{~kg}$, sulfuric acid concentration $1.5 \mathrm{~kg} / \mathrm{kg}$ clay, sugar fine powder $50 \mathrm{~g} / \mathrm{kg}$ clay, water $3000 \mathrm{ml} / \mathrm{kg}$ clay, and stirring time of $30 \mathrm{~min}$ at $100^{\circ} \mathrm{C}$. The morphology characterization showed that the deposited graphene oxide layer is in the nano form (6 to $33 \mathrm{~nm}$ ). Sets of experiments were conducted to evaluate the adsorption performance of synthesized NGOCB for removal of methylene blue (MB) dye from aqueous solutions. Effect of initial dye concentration, contact time, $\mathrm{pH}$ and temperature on the adsorption capacity of the modified adsorbent were studied. The capacity of the prepared nano graphene oxide coated bentonite adsorbent was $1000 \mathrm{mg} / \mathrm{g}$.

Conclusions: The removal efficiency of nano graphene coated clay reached to $99.9 \%$ that indicates the Egyptian bentonite could be employed as a low-cost absorbent for dye removal.
\end{abstract}

Keywords: Clay, Bentonite, Kaolinite, Feldspar, Adsorption, Graphene oxide, Methylene blue

\section{Background}

Water contamination is a serious problem for human society due to tens of thousands of dyes that exist in sewage waters from different industries such as food, textiles, cosmetics, paper, printing, carpets and leather. It is estimated that the quantity of dyes discharged in wastewater stream in the environment is about $1-2 \%$ loss during production and $1-10 \%$ loss during uses (Pandey and Ramontja 2016). As small quantities of dyes can badly impact on water bodies, it must be treated before disposal (Ramakrishna and Viraraghavan 1997). Most of the government organizations and water industries try to develop cost-

\footnotetext{
* Correspondence: hala.hussein21@yahoo.com

Chemical Engineering \& Pilot Plant Department, National Research Centre, Giza 12311, Egypt
}

\section{Springer Open}

(c) The Author(s). 2020 Open Access This article is licensed under a Creative Commons Attribution 4.0 International License, which permits use, sharing, adaptation, distribution and reproduction in any medium or format, as long as you give appropriate credit to the original author(s) and the source, provide a link to the Creative Commons licence, and indicate if changes were made. The images or other third party material in this article are included in the article's Creative Commons licence, unless indicated otherwise in a credit line to the material. If material is not included in the article's Creative Commons licence and your intended use is not permitted by statutory regulation or exceeds the permitted use, you will need to obtain permission directly from the copyright holder. To view a copy of this licence, visit http://creativecommons.org/licenses/by/4.0/.

effective technologies for wastewater treatment and reclamation due to increasing demand of fresh water (Toor 2010). Developing effective and low-cost adsorbents has great importance for controlling water contamination (Zhao et al. 2018). Adsorption is a surface phenomenon and interacts via physical forces with pollutants that may be adsorbed on the solid surface. However, weak chemical bonding may be also involved in the adsorption process (Pandey and Ramontja 2016). Moreover, it is known as an effective and economic procedure for wastewater purification. As it is simple in operation, it is a cost-effective and an efficient method for removal of both organic and inorganic pollutants from contaminated waters (Nigam et al. 1996; Annadurai et al. 2002). Currently, 


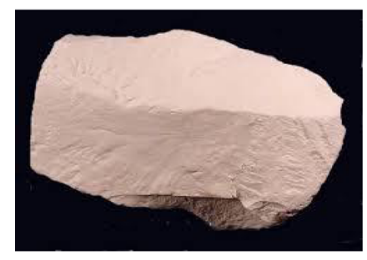

Photo (1) Kaolinite

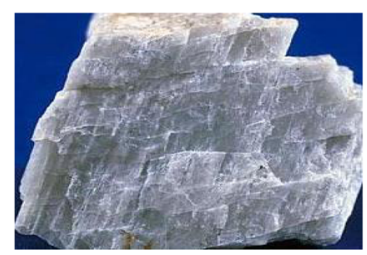

Photo (2) Bentonite

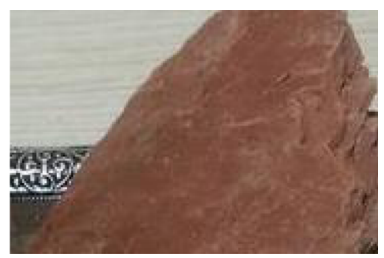

Photo (3) Feldspar

Fig. 1 Substrate clay pictures. Photo (1), kaolinite. Photo (2), bentonite. Photo (3), feldspar

activated carbon is the most commercial system that can be used as sorbent to remove dyes in wastewater (Sophia et al. 2019). In spite of its excellent adsorption ability, its application is restricted due to high cost (Derbyshire et al. 2001). Also, activated carbon has other drawbacks such as non-selective and ineffective against disperse and vat dyes, which force scientists to search for more economic adsorbents (Babel and Kurniawan 2003). For improving adsorption capacity of natural clay, various methods were proposed such as acid activation (Emmerich et al. 2009), treatment with cationic surfactant ( $\mathrm{He}$ et al. 2006), clay-rubber composite (Dai and Huang 1991), thermal treatment (Al-Asheh et al. 2003), polymer addition, plasma (de LB et al. 2008) adsorption and ion exchange with inorganic and organic cations, binding of inorganic and organic anions (mainly at the edges) and grafting of organic compounds (Liu 2007). Graphene oxide-calcium alginate composite has an absorptive capacity 20 times greater than acidactivated bentonite clay (Fatihaa and Belkacem 2016; $\mathrm{Li}$ et al. 2013). In this work, a novel technique was presented for conversion of bentonite clay into high adsorption capacity absorbent. The bentonite clay was used as a substrate for deposition of nano graphene oxide layer which has an expected absorptive capacity more than 100 times greater than activated carbon. The present work aims to use fine powder sugar in the presence of sulfuric acid to deposit a thin layer of graphene oxide over the clay surface to prepare nano structure nano graphene oxide coated bentonite with spherical surface morphology. Hence, the adsorption capacity of natural clay was improved. The prepared graphene oxide was investigated as highly efficient and low-cost adsorbent for wastewater treatment especially in dye removal from aqueous solutions or suspensions.

\section{Methods \\ Materials \\ Clay substrate}

Figure 1 shows the raw kaolinite, bentonite and feldspar bloke used in this study. Chemical composition of the used clays were provided in Table 1. Fine powder of sugar produced by El Hawamdeya Sugar Production Company in Egypt was used as carbon source for graphene oxide layer preparation. Sulfuric acid $98 \%$ was used for activation. All used reagents were of analytical grade.

The adsorbent was applied for removal of the basic dye methylene blue (MB), which is a heterocyclic aromatic compound, dark green, and solid at room temperature. The chemical structure of the MB is shown in Table 2.

The wavelength corresponding to the maximum absorbance $(\max )$ was detected at $660 \mathrm{~nm}$ using single beam (UV-Vis) spectrophotometer as shown in Fig. 2. This wavelength was selected to measure the absorbance of residual concentration of MB dye, while Fig. 3 shows the relation of $\mathrm{MB}$ concentration and the absorbance obtained at the optimum wave length $(660 \mathrm{~nm})$. The following equation is used to measure the dye concentration remained:

$$
\mathrm{Y}=0.2355 \mathrm{X}
$$

where $\mathrm{Y}$ is absorbance and $\mathrm{X}$ is $\mathrm{MB}$ dye concentration.

Table 1 Chemical composition of the used clays (Yahaya et al. 2017; Hassan and Abdel-Khalek 1998; Boulos et al. 2015)

\begin{tabular}{lllllllll}
\hline Clay & Total $\mathrm{SiO}_{2} \%$ & Free quartz (\%) & Combined $\mathrm{SiO}_{2} \%$ & $\mathrm{Al}_{2} \mathrm{O}_{3} \%$ & $\mathrm{H}_{2} \mathrm{O} \%$ & $\mathrm{MnO} \%$ & $\mathrm{MgO} \%$ & Other minerals (\%) \\
\hline Kaolinite & $\mathbf{2 9 . 1}$ & $\mathbf{8}$ & $\mathbf{2 1 . 1}$ & $\mathbf{3 6}$ & $\mathbf{4}$ & - & - & $\mathbf{1 . 2}$ \\
Bentonite & $\mathbf{5 4}$ & - & - & $\mathbf{1 7 . 0 1}$ & $\mathbf{1 4}$ & $\mathbf{0 . 0 8}$ & $\mathbf{2 . 4 7}$ & $\mathbf{1 2 . 4 4}$ \\
Feldspar & $\mathbf{7 3 . 5}$ & - & - & $\mathbf{1 2 . 5}$ & - & - & - & $\mathbf{1 4}$ \\
\hline
\end{tabular}


Table $\mathbf{2}$ Chemical composition of methylene blue

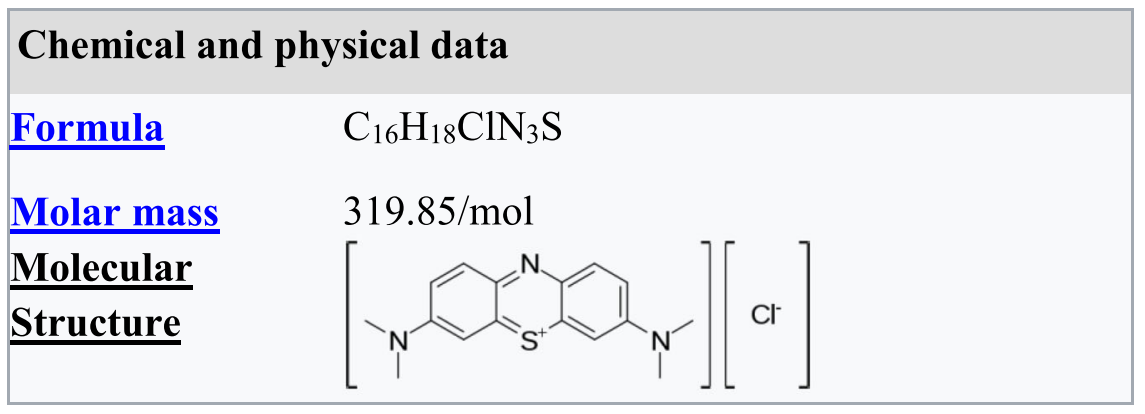

\section{Synthesis of adsorbents}

The bentonite clay was mixed with different weights of sugar as described in the following:

a. Clay grinding and sieving: kaolinite, bentonite and feldspar blokes were grinded then sieved to the desired particle size,

b. About $100 \mathrm{~g}$ of clay was mixed with fine powder sugar $(1-7 \mathrm{~g})$,

c. $200 \mathrm{ml}$ of concentrated sulfuric acid was added,

d. Heating the mixture gently till the hydration reaction started,

e. After the dehydration reaction completed, $300 \mathrm{ml}$ distilled water was added with stirring then the mixture is boiled for $30 \mathrm{~min}$ to activate the deposited graphene oxide layer,

f. After cooling, the filtration followed by washing was carried out till the $\mathrm{pH}$ reached to 7 ,

g. Then drying is carried out at $105^{\circ} \mathrm{C}$.

\section{Adsorption capacity}

Equilibrium experiments were performed to determine the adsorption capacity of the adsorbent as following: $0.5 \mathrm{~g}$ of the coated graphene oxide clay was added to 50 $\mathrm{ml}$ of $\mathrm{MB}$ solution $(100 \mathrm{mg} / \mathrm{l})$ then stirring for $5 \mathrm{~min}$ and filtration. After that, the absorbance of the filtrate was measured at $660 \mathrm{~nm}$ to determine the concentration of residual MB dye. The concentration and adsorption capacity of dye were calculated using the following equation:

$$
\begin{aligned}
& \text { Adsorption capacity }\left(\mathrm{q}_{\mathrm{e}}\right)=\left(\mathrm{C}_{\mathrm{i}}-\mathrm{C}_{\mathrm{f}}\right) * \mathrm{~V} / \mathrm{M} \\
& \text { Removal } \%=\frac{\mathrm{Ci}-\mathrm{Cf}}{\mathrm{Ci}} \times 100
\end{aligned}
$$

where $\mathrm{q}_{\mathrm{e}}(\mathrm{mg} / \mathrm{g})$ denote the equilibrium adsorption capacity,

$\mathrm{C}_{\mathrm{i}}$ is the initial concentration of $\mathrm{MB}(\mathrm{mg} / \mathrm{l})$,

$\mathrm{C}_{\mathrm{f}}$ is the final concentration of the $\mathrm{MB}(\mathrm{mg} / \mathrm{l})$,

$\mathrm{M}$ is the mass of the adsorbent (g),

and $\mathrm{V}$ is the volume of the dye solution (L).

\section{Clay coated graphene oxide morphology}

The shape and size of the obtained clay coated with graphene oxide was characterized using a JEOL-JEM-1200 transmission electron microscope (TEM). The TEM sample was prepared by adding a drop of the graphene oxide coated clay suspension solution after sonication for $15 \mathrm{~min}$ on a 400-mesh copper grid coated by an amorphous carbon film and lifting the sample to dry in air at room temperature. The average diameter of the clay coated particles was determined within 100

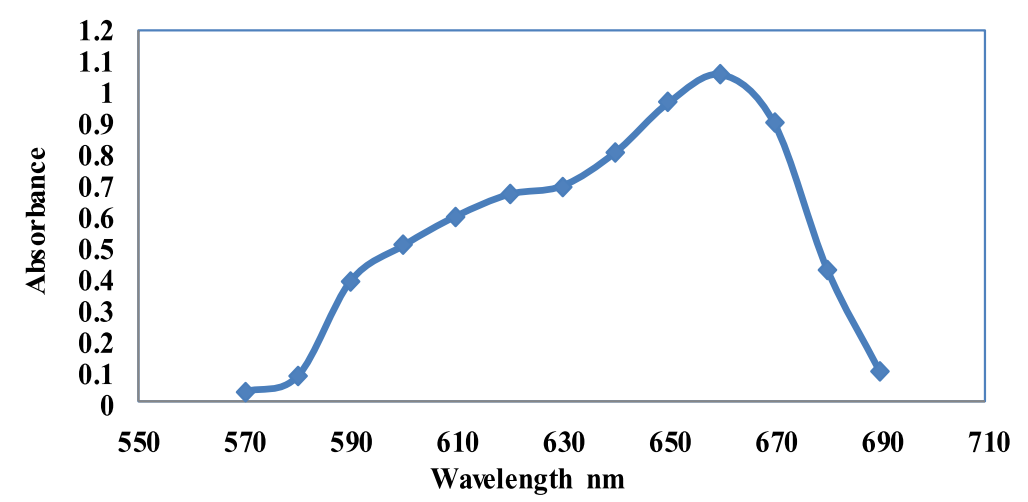

Fig. 2 Variation of absorbance of MB dye $(100 \mathrm{mg} / \mathrm{l})$ solution with wavelength 


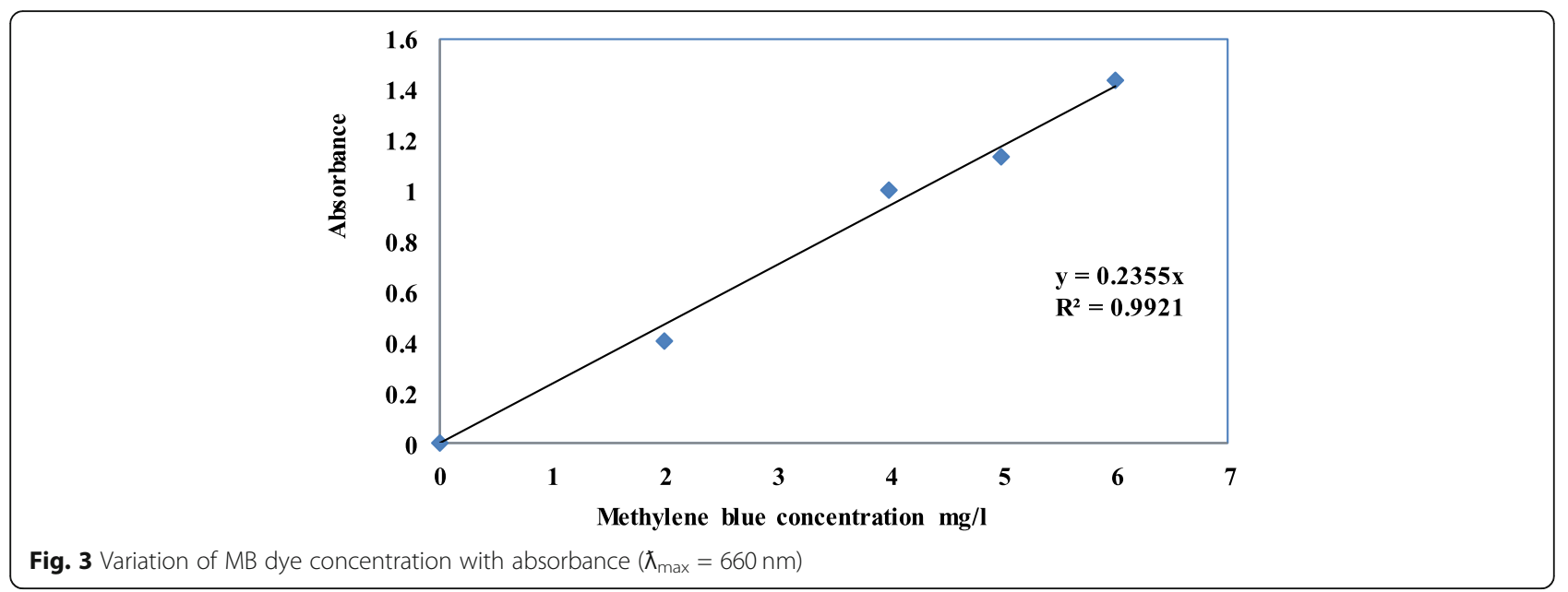

nanoparticles found in several chosen areas in enlarged microphotographs. Also, X-ray diffraction test was carried out using X-ray diffraction-type BRUKER apparatus, D8 ADVANCE, $\mathrm{Cu}$ target wavelength $1.54 \mathrm{~A} 40 \mathrm{kV}, 40$ mA (Germany).

\section{$X R D$ diffraction}

X-ray diffraction (XRD) scans of graphene oxide was performed with Bruker's D8 advanced X-ray diffractometer using $\mathrm{CuK} \alpha$ radiation $(\lambda=1.5418 \mathrm{~A})$. Dynamic light scattering (model no: HORIBA Nano particle analyzer SZ 100) was used to measure the size of the particle.

\section{Fourier transform infrared spectroscopy (FTIR)}

Fourier transform infrared spectroscopy (FTIR) was performed to identify types of chemical bonds, i.e. functional groups in a molecule (model no: Perkin Elmer precisely FT-IR spectrometer) over the wave number range of $4000-500 \mathrm{~cm}^{-1}$.

\section{Results}

\section{Effect of clay substrate type}

For nano graphene oxide layer deposition, the clay substrate (100 g), sugar (fine powder, $5 \mathrm{~g}$ ), sulfuric acid (54 $\mathrm{ml})$ and distilled water $(300 \mathrm{ml})$ were mixed and stirred for $30 \mathrm{~min}$ at $100^{\circ} \mathrm{C}$. On studying sulfuric acid as dehydrating solvent, it was found that both kaolinite and feldspar yields were decreased to 40 and $70 \%$, respectively. This may be attributed to dissolution of the substrate in the concentrated sulfuric acid medium due to the presence of free aluminum oxide as illustrated in Table 1 and other minerals such as sodium oxide, potassium oxide and others which are soluble in concentrated sulfuric acid. On the other hand, in the case of bentonite only $5 \%$ of the substrate dissolution was observed as shown in Fig. 4. Stability of bentonite clay may be attributed to the presence of aluminum in combined state with silica as montmorillonite which is insoluble hydrated sodium calcium aluminum magnesium silicate hydroxide $(\mathrm{Na}, \mathrm{Ca})_{0.33}(\mathrm{Al}, \mathrm{Mg})_{2}\left(\mathrm{Si}_{4} \mathrm{O}_{10}\right)(\mathrm{OH})_{2} \cdot \mathrm{nH}_{2} \mathrm{O}$. So, bentonite clay was selected as the optimum substrate for nano graphene oxide deposition based on the above discussion.

\section{Effect of sulfuric acid concentration}

The effect of sulfuric acid concentration on both the nano graphene oxide coated bentonite clay yield (adsorbent) and the adsorption efficiency for removal $\mathrm{MB}$ dye is graphically shown in Fig. 5. On studying the effect of sulfuric acid addition in synthesis of graphene oxide coated bentonite clay, it was clear that as the sulfuric acid concentration increases, the coated clays by graphene oxide yield decreases from $98 \%$ at sulfuric acid dose $50 \mathrm{~g} / 100 \mathrm{~g}$ clay to $55 \%$ at $250 \mathrm{~g} / 100 \mathrm{~g}$ clay. On the other hand, as the sulfuric acid amount increases from $150 \mathrm{gm} / 100 \mathrm{gm}$ to $250 \mathrm{gm} / 100 \mathrm{gm}$ clay, the adsorption capacity of NGOCB for MB solution increases from 60 to $98 \%$. So, the amount of sulfuric acid $150 \mathrm{~g} / 100 \mathrm{~g}$ clay was selected as optimum.

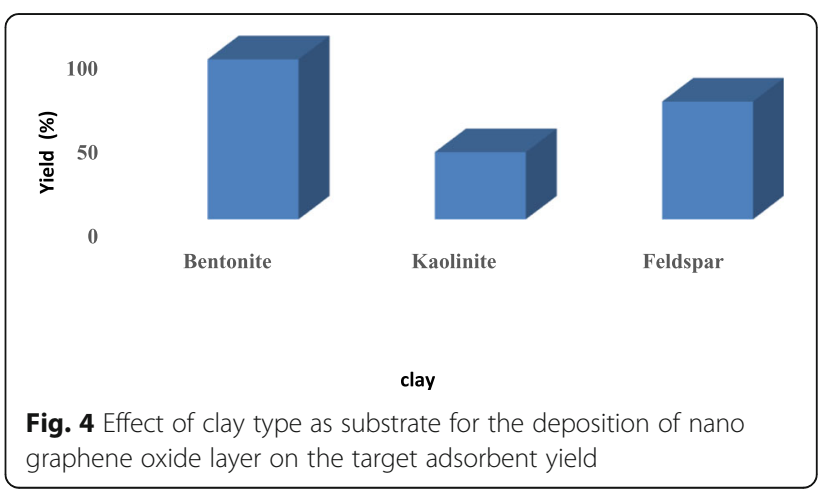




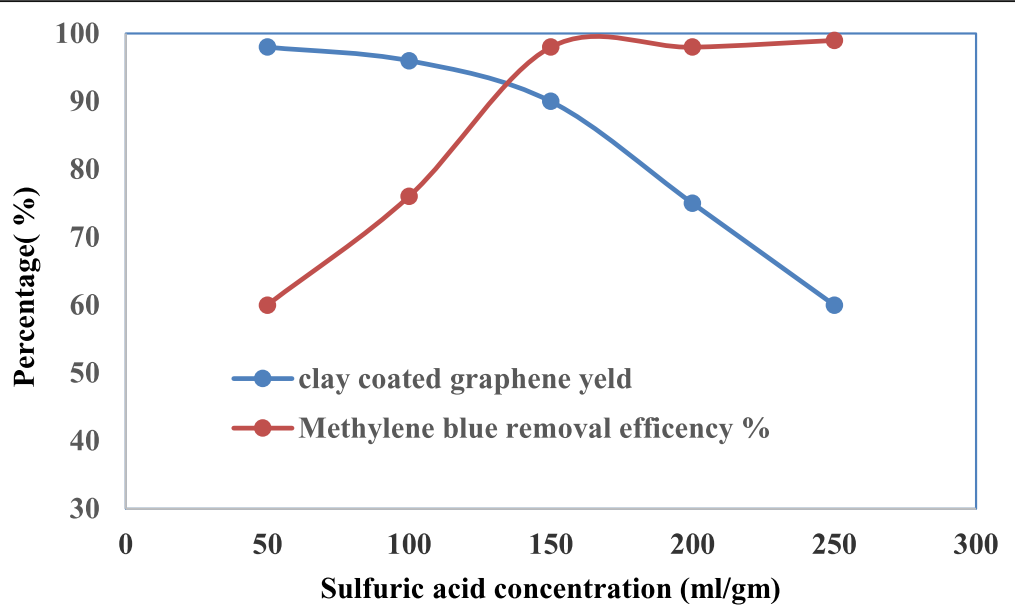

Fig. 5 Effect of sulfuric acid concentration on the clay coated graphene oxide yield and methylene blue removal efficiency, (bentonite substrate $100 \mathrm{~g}$, sugar fine powder $5 \mathrm{~g}$, water $300 \mathrm{ml}$, and stirring time $30 \mathrm{~min}$ at $100^{\circ} \mathrm{C}$ )

\section{Effect of sugar concentration}

Addition of sugar on bentonite with different amounts was studied. Figure 6 shows the effect of sugar concentration on both bentonite graphene oxide coated clay yield and $\mathrm{MB}$ removal efficiency from its solution. It is clear that as the sugar concentration increased above $50 \mathrm{~g} / \mathrm{kg}$ clay, no change of bentonite graphene oxide coated clay yield was observed. This may be attributed to that certain outer surface area of the bentonite substrate which will be saturated with fixed amount of graphene formed from the dehydration of sugar powder. While the sugar fine powder concentration increases, the removal efficiency of the methylene blue from the solutions increases reaching $98 \%$ at optimum sugar dose. From the abovementioned results, it is concluded that the optimum operating conditions for the synthesis of bentonite coated by nano graphene oxide layer using sugar fine powder as source of carbon were bentonite substrate $1 \mathrm{~kg}$, sulfuric acid concentration $1.5 \mathrm{~kg} / \mathrm{kg}$ clay, sugar fine powder $50 \mathrm{~g} / \mathrm{kg}$ clay, water $3000 \mathrm{ml} / \mathrm{kg}$ clay, and stirring time $30 \mathrm{~min}$ at $100^{\circ} \mathrm{C}$. Figure 7 illustrates the shape and color of the obtained adsorbent due to the change of sugar powder addition; it is clear that as the sugar dose increases, the color changes from buff to black which indicates the formation of graphene oxide layer.

\section{Preparation of nano fertilizer from acid waste}

After the activation process, the resulted slury is filterted to get the graphene oxide coated bentonite. The filtrate

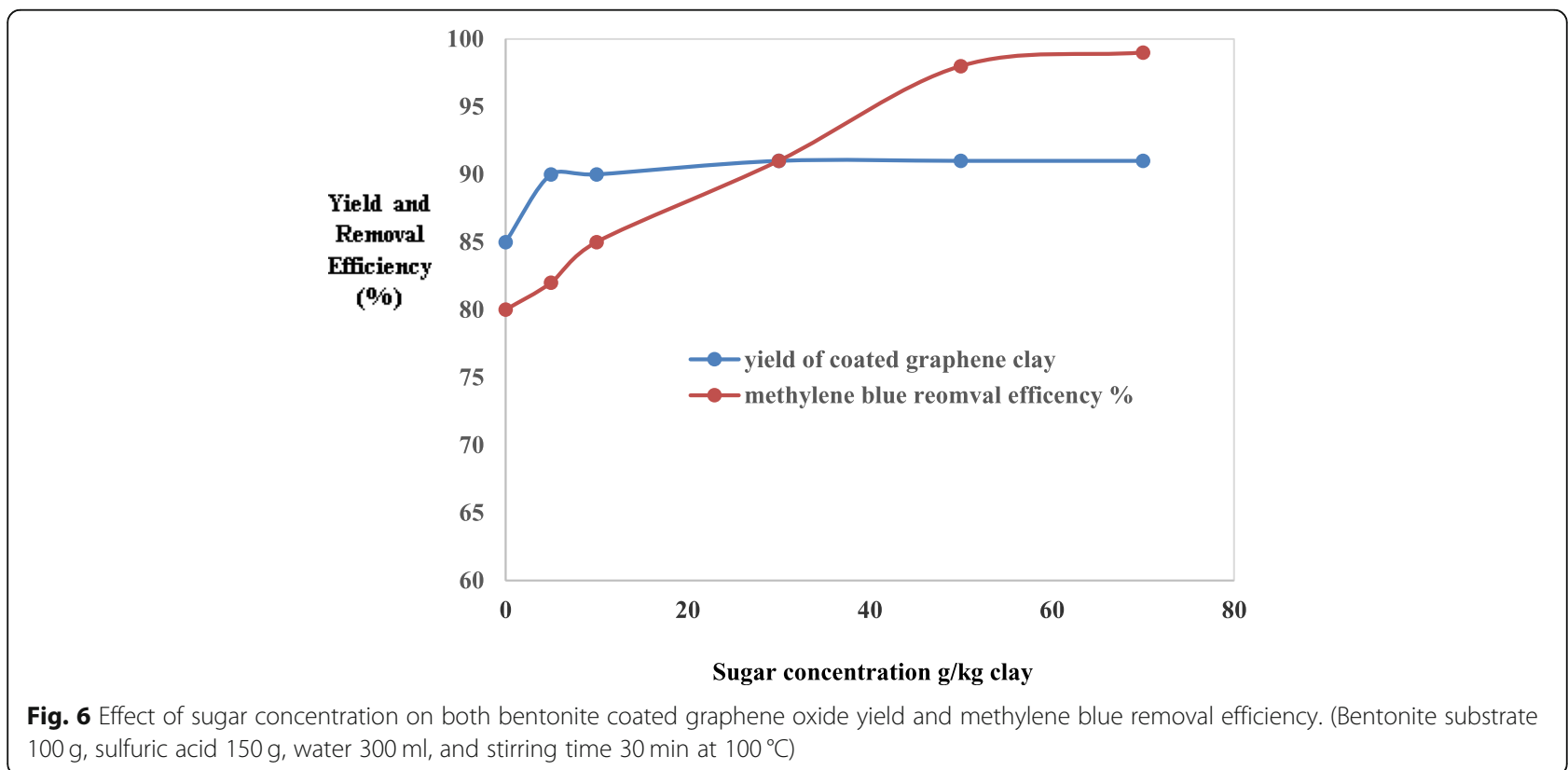




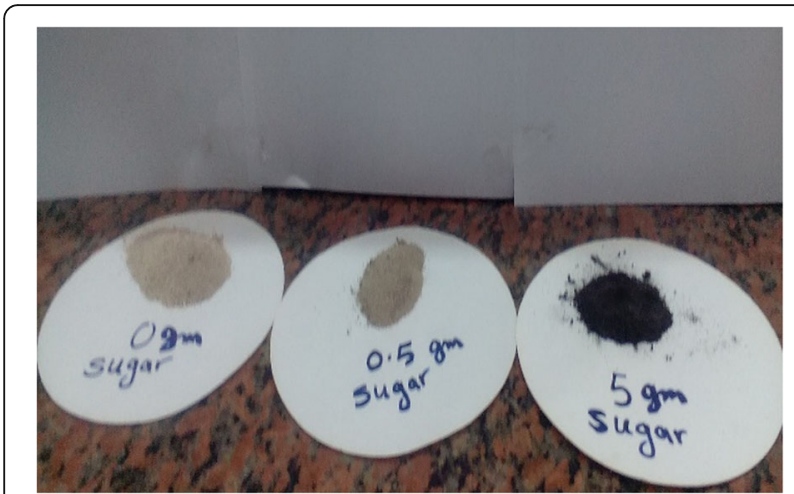

Fig. 7 Photo of adsorbent shape and color

is mainly highly concentrated sulfuric acid solution. This acid solution may be used for prepration of nano fertilizer to reach the so-called zero liquid discharge (ZLD) process as mentioned previously by Hussein et al. 2019.

\section{Adsorption capacity optimization}

In order to get the maximum adsorption capacity of the prepared nano graphene oxide coated bentonite for $\mathrm{MB}$ removal, several operating conditions have to be investigated such as nano graphene oxide adsorbent dose, stirring time, initial $\mathrm{MB}$ solution $\mathrm{pH}$ and temperature.

Effect of NGOCB clay amount on the adsorption efficiency The removal efficiency of MB dye $100 \mathrm{mg} / \mathrm{l}$ with different doses of bentonite coated with nano graphene oxide layer prepared via the optimum operating conditions mentioned above were represented in Fig. 8. The adsorption experiments were carried out at a stirring time of $15 \mathrm{~min}$ with a stirring rate of $150 \mathrm{rpm}$ then settling for $10 \mathrm{~min}$ and filtration of the decanted solution. It is clear from this data that as the dose of the coated clay increases, the adsorption efficiency increases reaching its maximum (98\%) at $15 \mathrm{~min}$ for $20 \mathrm{~g} / \mathrm{l}$.

\section{Effect of NGOCB dose on contact time}

The removal efficiency was studied at different time intervals as shown in Fig. 9. It illustrates that the uptake attained equilibrium after $15 \mathrm{~min}$ for $\mathrm{NGOCB}$ and the removal efficiency reached $98 \%$, while in literature the time needed for equilibrium was $3 \mathrm{~h}$ (Pandey and Ramontja 2016). These results revealed that the stirring time is inversely proportional to the quantity of adsorbent, i.e. increasing dose of NGOCB decreases the time required for maximum removal. On using $1 \mathrm{~g}$ of coated clay per one liter of $\mathrm{MB}$ solution $(100 \mathrm{ppm})$, the time required was $60 \mathrm{~min}$ to reach to maximum removal of dye, while on adding a dose of $20 \mathrm{~g} / \mathrm{l}$, the time required was only $15 \mathrm{~min}$ for complete removal. So, from the economical point of view and the engineering design parameters, it is recommended to use the dose $5 \mathrm{~g} / \mathrm{l}$ for $40 \mathrm{~min}$ as a considerable amount and a short time was required.

\section{Effect of initial pH}

As shown in Table 3, the adsorption of the dye with $\mathrm{pH}$ from 4 to 11 were studied, keeping all other parameters constant. It was observed that the amount of dye absorbed per unit weight of absorbent increased as the increasing $\mathrm{pH}$ value. This is due to electrostatic force between the adsorbent and positively charged basic dyes which become less. This is in good agreement with the results reported before (Pandey and Ramontja 2016).

\section{Effect of temperature}

By increasing the temperture of MB solution from 25 to $60^{\circ} \mathrm{C}$, it is clear that increasing the temperature increases the pecent removal of $\mathrm{MB}$ from 99 to $99.6 \%$ at $40{ }^{\circ} \mathrm{C}$ then it remains constant at $60^{\circ} \mathrm{C}$ which means that the temperature almost has no effect on NGOCB adsorption capacity throughout this study as shown in Table 4.

\section{Graphene oxide coated bentonite surface morphology}

The sample of the NGOCB (bentonite coated with nano graphene oxide) prepared at the optimum conditions was studied by TEM test and SAED (a and c) to obtain

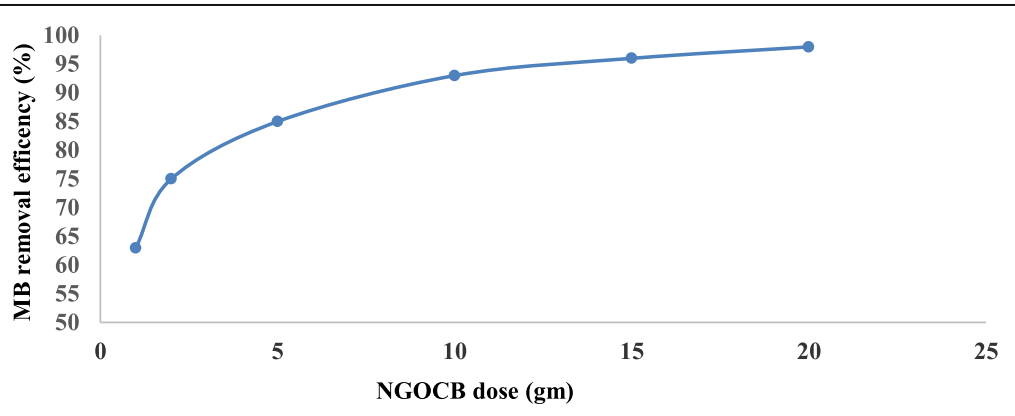

Fig. 8 Effect of NGOCB dose on the removal efficiency of methylene blue (pH 7, stirring time 15 min, room temperature, stirring rate 150 rpm) 


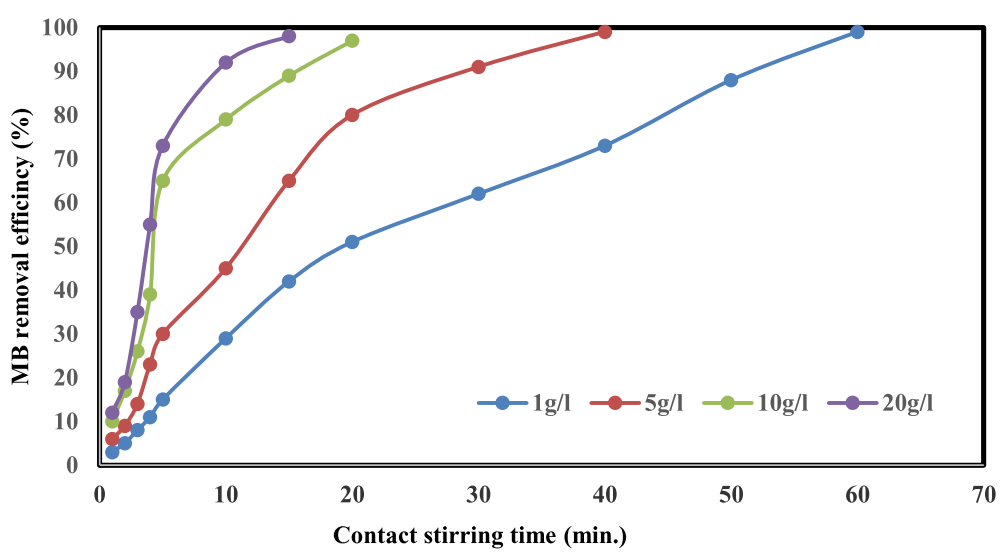

Fig. 9 Effect of contact stirring time on MB removal efficiency at different doses of NGOCB. (MB 100 mg/l, pH 7 at RT)

the surface morphology. It was found that the obtained particles are in spherical shape with a diameter that ranged from 6 to $33 \mathrm{~nm}$ as shown in photo (a) and the histogram (b) of the prepared sample which was shown in Fig. 10. The histogram shows that the major particle sizes present of the optmium NGOCB (42\%) is $6 \mathrm{~nm}$ while the minor particle sizes is $33 \mathrm{~nm}$ which represents $5 \%$ of the sample. The selected area electronic diffraction pattern (SAED) (c) test illustrates that the obtained coat over the bentonite clay is defintely graphene oxide layer. The presence of internal points with higher light intensities than other external points clearly indicated the presence of graphene oxide mono-layers with hexagonal pattern and structure containing a smaller number of layers, which is in good agreement with the results of previous work (Hack et al. 2018). X-ray diffraction of nano graphene oxide was performed to determine the crystal structure of graphene oxide obtained by this method. As shown in Fig. 11, it gave one sharp peak for graphene oxide at $15.59^{\circ}$. Also, it indicated that graphite was completely oxidized to graphene oxide due to the disappearance of graphite peak at $10.5^{\circ}$. Moreover, the interlayer distance of graphene oxide (d spacing) was calculated $(0.077 \AA)$. The compositional analysis of graphene oxide was performed with the aid of FTIR (Fig. 12) over the range of $390-3890 \mathrm{~nm}$. The wide band observed in graphene oxide between 3500 and 3100 is attributed to the $\mathrm{O}-\mathrm{H}$ (hydroxyl group), stretching vibrations of $\mathrm{C}-\mathrm{OH}$ and observed water molecules. The peak observed at 1627 is due to the combined effect of $\mathrm{C}=\mathrm{C}$ and $\mathrm{C}=\mathrm{O}$ vibrations. The adsorption bands between 850 and $800 \mathrm{~nm}$ are credited to the $\mathrm{C}-\mathrm{H}$ bond

Table 3 Effect of pH solution on MB removal efficiency

\begin{tabular}{lllll}
\hline $\mathrm{pH}$ & 4 & 7 & 9 & 11 \\
\hline Removal efficiency (\%) & 50 & 72 & 99 & 99 \\
\hline
\end{tabular}

vibration. Also, spikes at $650-600 \mathrm{~nm}$ arise from $\mathrm{C}-\mathrm{H}$ bonding vibration.

\section{Adsorption capacity of the graphitized clay}

The graphene oxide source in this study is the dehydration reaction of fractose according to Eq. 4:

$$
\left.\mathrm{C}_{12} \mathrm{H}_{22} \mathrm{O}_{11} \text { (sugar }\right)+\mathrm{H}_{2} \mathrm{SO}_{4} \rightarrow 12 \mathrm{C}+11 \mathrm{H}_{2} \mathrm{O}+\mathrm{H}_{2} \mathrm{SO}_{4}
$$

The complete dehydration of one mole of sugar (180 g) will give $72 \mathrm{~g}$ of carbon. With respect to our results, 5 g sugar/100g bentonite clay was selected as optmium. Then, $5 \mathrm{~g}$ sugar will give $2 \mathrm{~g}$ carbon per $100 \mathrm{~g}$ clay, i.e. $20 \mathrm{~g}$ graphene oxide/kg bentonite clay.

The results show that $5 \mathrm{~g}$ of the NGOCB is cabable for the removal of $100 \mathrm{mg}$ of $\mathrm{MB}$ dye from its solution. This means that $100 \mathrm{mg}$ net graphene oxide coat is cabable for removal of $100 \mathrm{mg}$ of MB dye. By calculations, $1 \mathrm{~g}$ of net graphene oxide coat could remove $1000 \mathrm{mg}$ of $\mathrm{MB}$ dye from its solution which indicates that the adsorption capacity of the NGOCB adsorbent is $1000 \mathrm{mg} / \mathrm{g}$ adsorbent which is more than five times than that cited in the previous work ( $\mathrm{Li}$ et al. 2013). It is expected to increase the adsorption capacity about 10 times by improving the conversion of graphene oxide to graphene layer by reduction process to modify the adsorbent which will require more investigation.

According to the traditional graphene oxide-calcium alginate composite with MB adsorption capacity (183 $\mathrm{mg} / \mathrm{g}$ ) which was prepared by the Hummer method (Li et al. 2013) and comparing this with our prepared graphitized bentonite with adsorption capacity (1000 $\mathrm{mg} / \mathrm{g}$ net graphene), and with using a filtration process to evaluate both types in removal of $\mathrm{MB}$ with fixed volumes of them, it is found that our filter has removal efficency of 36 times more than that of 
Table 4 Effect of temperature solution on MB removal efficiency

\begin{tabular}{ll}
\hline Temp $\left({ }^{\circ} \mathrm{C}\right)$ & Removal efficiency $(\%)$ \\
\hline 25 & 99 \\
40 & 99.6 \\
60 & 99.6 \\
\hline
\end{tabular}

traditional graphene oxide-calcium alginate using the same dose at the same contact time. On the other hand, regarding the cost of NGOCB against the traditional one, it was found that the capital cost of NGOCB was about $30 \%(350 \$ / \mathrm{kg})$ of the traditional graphene capital cost $(1100 \$ / \mathrm{kg})$.

\section{Discussion}

Graphene oxide coated bentonite in nano form $\left(\mathrm{N}_{\mathrm{GOCB}}\right)$ was prepared by the dehydration reaction of sugar powder using concentrated sulfuric acid in the presence of Egyptian bentonite clay as carrier substrate followed by thermal activation in aqueous medium. Several operating parameters were studied to get the optimum preparation conditions such as the type of substrate, sulfuric acid concentration and sugar powder concentration, and the prepared adsorbent samples' adsorption capacity were tested using methylene blue dye as adsorbate. The surface morphology, FTIR, TEM and XRD of the optimum adsorbent sample was carried out to get a complete characterization of the target nano graphene oxide coated bentonite powder. The optimum preparation conditions were bentonite substrate $1 \mathrm{~kg}$, sulfuric acid concentration $1.5 \mathrm{~kg} / \mathrm{kg}$ clay, sugar fine powder $50 \mathrm{~g} /$ $\mathrm{kg}$ clay, water $3000 \mathrm{ml} / \mathrm{kg}$ clay, and stirring time 30 $\min$ at $100^{\circ} \mathrm{C}$. The selection of the substrate clay is based on the resistance of the clay to the sulfuric acid dissolution to maximize the amount of adsorbent yield. It was found that the bentonite structure has the lowest solubility in sulfuric acid flowed by feldspar, then kaolinite. This may be attributed to that the bentonite structure has aluminum in combined state with silica as montmorillonite which is insoluble hydrated sodium calcium aluminum magnesium silicate hydroxide $(\mathrm{Na}, \mathrm{Ca})_{0.33}(\mathrm{Al}, \mathrm{Mg})_{2}\left(\mathrm{Si}_{4} \mathrm{O}_{10}\right)(\mathrm{OH})_{2} \cdot \mathrm{nH}_{2} \mathrm{O}$. This formula is always used for the preparation of bleaching earth (RREF) due to its resistance to acid dissolution, so bentonite was selected as the optimum substrate for deposition of graphene oxide layer. At the optimum conditions, it will be sure that all the sugar amounts is consumed and converted to graphene oxide, and excess amount of sulfuric acid may leach the deposited graphene oxide layer to the activation medium

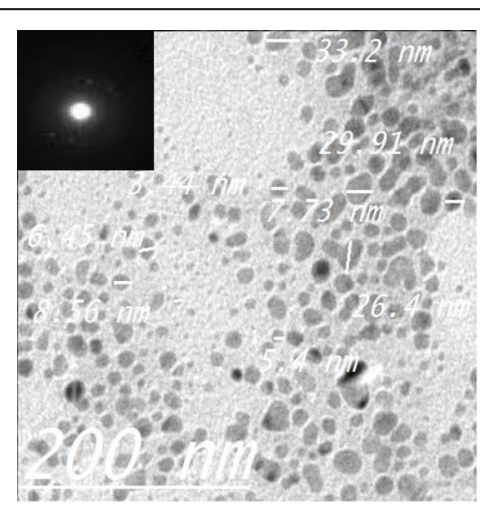

(a)

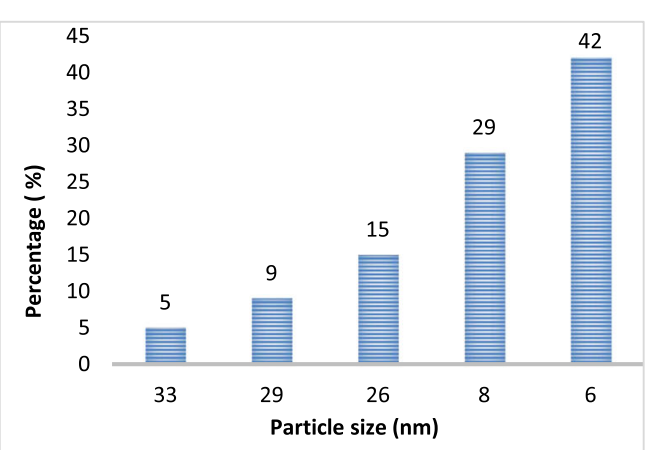

(b)

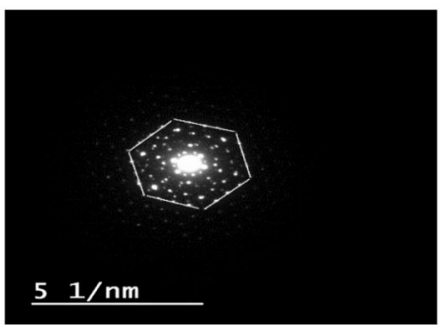

(c)

Fig. 10 a TEM analysis, $\mathbf{b}$ histogram, and $\mathbf{c}$ photo SAED of graphetized bentonite 


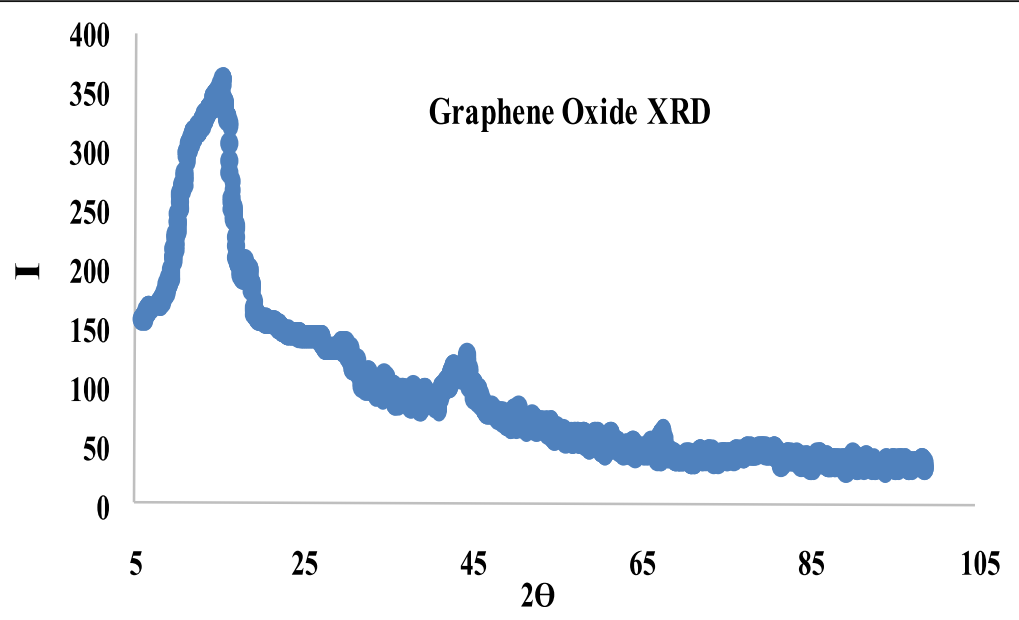

Fig. 11 XRD of obtained graphene

which leads to the decrease of the adsorption capacity; so, $150 \mathrm{~g} / \mathrm{kg}$ clay of sulfuric acid is considered as optimum. Regarding sugar powder amount, it is believed that the precipitated graphene oxide layer have to be in the form of one to nine layers to be as graphene or graphene oxide, while if more than nine layers it will be deposited as a graphite layer which has an adsorption capacity less than that of graphene or graphene oxide. So, at the optimum selected sugar dose is suitable for the maximum methylene blue dye removal which has matching presence of graphene oxide layer. Due to the concept of ZLD (zero liquid discharge), the wastewater carried during this process is mainly sulfuric acid solution with a minimum amount of nano carbon particles, so by the neutralization of this water by potassium hydroxide liquid nano fertilizer, it will be prepared with high cash flow in the production process as shown by Hussein et al. (2019). Several adsorption conditions were studied to maximize the obtained adsorbent (NGOCB) adsorption capacity of methylene blue dye from its solutions; these conditions were NGOCB dose, $\mathrm{pH}$, contact time, temperature and initial dye concentration. From experimental results, it was found that the optimum adsorption condtions were $\mathrm{pH} 11$, contact time $40 \mathrm{~min}, 5 \mathrm{~g} \mathrm{NGOCB} / \mathrm{l}$ of $100 \mathrm{mg} / \mathrm{l}$ methylene blue, temperature $25^{\circ} \mathrm{C}$. From the TEM analysis, the obtained NGOCB has spherical particles of diameter that ranged from 6 to $33 \mathrm{~nm}$ with a major percentage of $42 \%$ of $6 \mathrm{~nm}$ particles and 3\% of minor percentage of $33 \mathrm{~nm}$ particles as indicated by histogram. SAED and XRD analyses indicate the presence of monolayer graphene oxide over the surfaces of the bentonite clay with hexagonal structure.

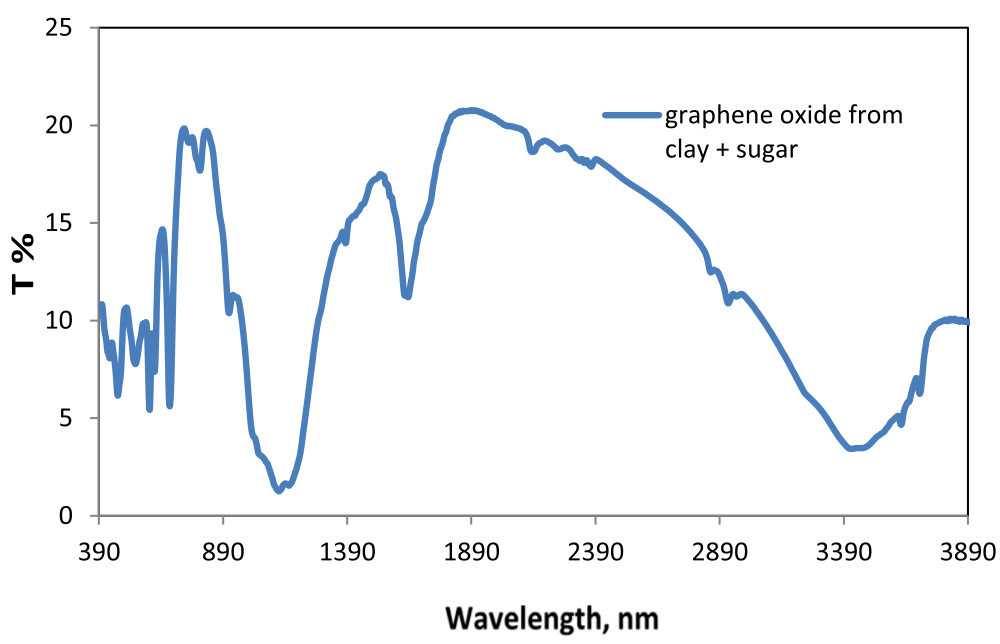

Fig. 12 FTIR analysis for synthesized nano graphene 


\section{Conclusions}

The adsorption of basic dye methylene blue was investigated using Egyptian bentonite clay coated with graphene oxide layer, and it was concluded that:

The optimum conditions for maximum adsorption capacity of MB dye by NGOCB were $150 \mathrm{~g}$ sulfuric acid per $100 \mathrm{~g}$ bentonite clay and using $5 \mathrm{~g}$ fine sugar powder.

Addition of sugar improves the removal of methylene blue to reach $99.95 \%$ at $15 \mathrm{~min}$ due to the increase in the adsorption capacity of graphene oxide coated bentonite.

The syntheized NGOCB, at the optmium conditions, has a nano size structure ranged from 6 to $33 \mathrm{~nm}$.

Adsorption behaviour was insensitive to the temperature change due to low activation energy in the ionic system.

Increasing the dose of NGOCB decreases the time required for maximum removal of dye. The net adsorption capacity of graphene oxide layer coated over bentonite clay is raised to $1000 \mathrm{mg} / \mathrm{g}$ which is more than five times the adsorption capacity of graphene oxide-calcium alginate composite.

\section{Abbreviations}

GO: Graphene oxide; NGOCB: Nano graphene oxide coated bentonite; MB: Methylene blue; XRD: X-ray diffraction; TEM: Transmission electronic microscope; SAED: Selected area electron diffraction; FTIR: Fourier transform infrared spectroscopy

\section{Acknowledgements}

The authors would like to express their appreciation to the National Research Centre Fund for the financial support and many thanks for central lab in NRC and all the teamwork

\section{Authors' contributions}

This work is a combined effort of all of the authors. $\mathrm{NH}$ and EA conducted the experimental section. SI, HH and HS participated in the development and implementation of the research plan and subsequently written it. All authors read and approved the final manuscript.

\section{Funding}

This work was done in the National Research Centre, Egypt, which has funded all the experimental work.

\section{Availability of data and materials \\ Not applicable}

\section{Ethics approval and consent to participate}

Not applicable

\section{Consent for publication}

Not applicable

\section{Competing interests}

The authors declare that they have no competing interests.

Received: 15 March 2019 Accepted: 12 March 2020

Published online: 14 April 2020

\section{References}

Al-Asheh S, Banat F, Abu-Aitah L (2003) Adsorption of phenol using different types of activated bentonite. Sep Pur Tech. 33:1-10

Annadurai G, Juang RS, Lee DJ (2002) Use of cellulose-based waste for adsorption of dyes from aqueous solutions. J Hazardous Mater B92:263-274

Babel S, Kurniawan TA (2003) Low-cost adsorbents for heavy metals uptake from contaminated water: a review. J Hazardous Mater. B97:219-243
Boulos TR, Ibrahim SS, Yehia A (2015) Differential flotation of some Egyptian feldspars for separation of both silica and iron oxides contaminants. J Minerals Mater Characterization Eng 3:435-443

Dai JC, Huang JT (1991) Surface modification of clays and clay rubber composite. Appl Clay Sci. 15:51-65

de LB P, Morales AR, FRV D, Organoclays (2008) Properties, preparation and applications. Appl Clay Sci. 42:8-24

Derbyshire F, Jagtoyen M, Andrews R, Rao A, Martin-Gullon I, Grulke E (2001) Carbon materials in environmental applications. In: Radovic LR (ed) Chemistry and Physics of Carbon, vol 27. Marcel Dekker, New York, pp 1-66

Emmerich K, Steudel A, Weidler P (2009) Alteration of swelling clay minerals by acid activation. Appl Clay Sci. 44:105-115

Fatihaa M, Belkacem B (2016) Adsorption of methylene blue from aqueous solutions using natural clay. J Mater Environ Sci. 7(1):285-292

Hack R, Correia C, De Simone Zanon RA, Pezzin SH (2018) Characterization of graphene nano sheets obtained by a modified Hummer's method, Matéria (Rio J.) vol.23 no.1 Rio de Janeiro.

Hassan MS, Abdel-Khalek NA (1998) Beneficiation and applications of an Egyptian bentonite. Appl Clay Sci 13:99-115

He H, Frost RL, Bostrom T, Yuan P, Duong L, Yang D, Xi Y, Kloprogge T (2006) Changes in morphology of organo clays with HDTMA surfactant loading. Appl Clay Sci. 31:262-271

Hussein HS, Shaarawy HH, Hussien Nabila H, Hawash SI (2019) Preparation of nano-fertilizer blend from banana peels. Bull Natl Res Centre 43:26

Li Y, Du Q, Liu T, Sun J, Wang Y, Wu S, Wang Z, Xia Y, Xia L (2013) Methylene blue adsorption on graphene oxide/calcium alginate composites. Carbohydrate Polymers 95(1):501-507

Liu P (2007) Polymer modified clay minerals: a review. Appl Clay Sci. 38:64-76

Nigam P, Banat IM, Singh D, Marchant R (1996) Microbial process for the decolorization of textile effluent containing azo, diazo and reactive dyes. Process Biochem 31(5):435-442

Pandey S, Ramontja J (2016) Natural bentonite clay and its composites for dye removal: current state and future potential. Am J Chem Appl 3(2):8-19

Ramakrishna KR, Viraraghavan T (1997) Dye removal using low cost adsorbent Wttl. Sri Tick. 36(2-3):189-196

Sophia C, Arfin T, Lima EC (2019) Recent developments in adsorption of dyes using graphene based nanomaterials, in a book: A New Generation Material Graphene: Applications in Water Technology

Toor MK (2010) Enhancing adsorption capacity of bentonite for dye removal: physiochemical modification and characterization Master thesis in Engineering Science.

Yahaya S, Jikan SS, Badarulzaman NA, Adamu AD (2017) Chemical composition and particle size analysis of kaolin, Path of Science: International Electronic Scientific Journal, Vol. 3, No 10.

Zhao W, Zhu J, Wei W, Ma L, Zhu J, Xie J (2018) Comparative study of modified/ non-modified aluminum and silica aerogels for anionic dye adsorption performance. RSC Adv. 8:29129

\section{Publisher's Note}

Springer Nature remains neutral with regard to jurisdictional claims in published maps and institutional affiliations.

\section{Submit your manuscript to a SpringerOpen ${ }^{\circ}$ journal and benefit from:}

- Convenient online submission

- Rigorous peer review

- Open access: articles freely available online

- High visibility within the field

Retaining the copyright to your article

Submit your next manuscript at $>$ springeropen.com 